\title{
INTERAKSI KOMPONEN SUSTAINABLE LIVELIHOOD MEMENGARUHI PILIHAN PENGGUNAAN AIR BERSIH PADA KOMUNITAS URBAN DI KAWASAN PERMUKIMAN KUMUH
}

\author{
Moh. Fairuz Abadi, S.Si, M.Si \\ Mahasiswa Program Doktor Ilmu Kesehatan Masyarakat, Fakultas Kedokteran, \\ Universitas Udayana, Jl.PB. \\ Sudirman, Denpasar-Bali, IIndonesia \\ E-mail: zabadnews@gmail.com
}

\begin{abstract}
ABSTRAK
Latar belakang. Air bersih menjadi kebutuhan sehari-hari untuk hidup sehat dan produktif. Permukiman kumuh adalah kawasan padat penduduk di perkotaan yang berkaitan erat dengan permasalahan urbanisasi dan kemiskinan. Tujuan penulisan paper adalah untuk mereview penelitian yang berkaitan dengan lima komponen livelihood assets, yaitu modal sumber daya manusia, sosial, alam, finansial dan fisik terhadap akses sumber air bersih di komunitas urban permukiman kumuh. Metode, menggunakan literature review, kriteria inklusi yang digunakan adalah penelitian yang pernah dilakukan dalam kurun waktu 2009-2014, membahas kebijakan penyediaan air bersih dan sosial determinan. Pada PubMed didapatkan 329 artikel dan pada Ebsco Host 176. Seleksi berdasarkan kriteria inklusi didapatkan 10 artikel pada PubMed dan 3 pada Ebsco Host. Hasil. Artikel berasal dari di kota-kota mewakili kawasan Amerika, Eropa, Asia, Afrika dan Australia. Komponen sustainable livelihood tidak berdiri sendiri, interaksi antar komponen sustainable livelihood mempengaruhi pilihan penggunaan air bersih. Tingginya angka buta huruf dan putus sekolah menjadi faktor pembatas dalam modal sumber daya manusia dan finansial. Modal sumber daya alam dipengaruhi oleh dua faktor, yaitu pergantian musim, dan tingginya kontaminasi. Pada bidang modal sosial perlu dilakukan perubahan strategi kebijakan melalui penguatan pemberdayaan masyarakat, perlindungan sosial dan partisipasi sosial. Sumber daya fisik yang dikembangkan adalah sistem pemipaan, penyediaan air kemasan dan tekn ologi daur ulang air. Proses peningkatan derajat kesehatan masyarakat melalui peningkatan akses air bersih juga dipengaruhi oleh regulasi lokal dan keputusan politik. Simpulan Akses air bersih untuk komunitas urban di permukiman kumuh dipengaruhi oleh interaksi antar komponen livelihood assets dan kebijakan politik.
\end{abstract}

\footnotetext{
ABSTRACT

Background. Clean waters become a daily needs of healthy and productive life. Slums are densely populated urban area which is closely related to problems of urbanization and poverty. The purpose of this paper is to review research related to the five capital of Sustainable livelihood assets: namely human, social natural, financial and physical capital for access of clean water in urban slum communities. Methods, using literature review, inclusion criteria, are all of studies that have been conducted in the period 2009-2014, the water supply policy and social determinants. On the PubMed found 329 and at Ebsco Host 176 research articles. The selection are based on criteria found 10 articles in PubMed and
} 
10 on Ebsco Host. Results. The study are come from many cities that representing of the Americas, Europe, Asia, Africa, and Australia. Sustainable livelihood capital does not stand alone, the interaction of capital influences the choice of water use. High illiteracy and dropout becomes a limiting factor in human and financial capitals. The natural capitals influenced by two factors, the change of seasons, and the high contamination. In social capital necessary to change the strategy of policy through strengthening community empowerment, social protection and social inclusion. Physical capitals are developed piping systems, supply of bottled water and recycle technology. Clean water access is also affected by local regulations and political.Conclusions. Clean water acces for urban slum communities affected by the interaction between the components of livelihood assets and also the policies.

Key words Sustainable livelihood, water use, slum.

\section{PENDAHULUAN}

Permukiman kumuh berkaitan erat dengan permasalahan kemiskinan di perkotaan dan juga urbanisasi (Ismawan 2008). Alih fungsi lahan telah menurunkan daya dukung lingkungan dan kontaminasi air tanah (Abadi 2011). Permukiman kumuh memerlukan perhatian dalam rangka mencari solusi terhadap permasalahan penggunaan air bersih.

Interkasi komponen sustainable livelihood mempengaruhi pilihan penggunaan air bersih dalam kehidupan komunitas urban di permukiman kumuh. Komponen sustainable livelihood adalah human capital (modal sumber daya manusia), natural capital (modal sumber daya alam) social capital (modal sumber daya sosial), financial capital (modal sumber daya ekonomi) dan physical capital (modal sumber daya fisik).

Melalui pendekatan The Sustainable Livelihoods framework dapat dijelaskan bagaimana sistem modal masyarkat berinteraksi dengan lingkungan eksternal, yaitu berupa konteks kebijakan (policy) dan lingkungan alamiah (Carloni dan Eve Crowly, 2005). Sebuah kebijakan yang baik, membuat masyarakat yang tinggal di daerah kumuh lebih mudah untuk mendapatkan akses air bersih. Sebaliknya, kebijakan yang kontradiktif dapat mendiskriminasikan masyarakat sehingga sulit bagi mereka untuk mendapatkan akses penggunaan air bersih.

\section{METODE PENELITIAN}

Pengumpulan artikel dilakukan mengunakan computer melalui aplikasi software Mendeley. Kriteria inklusi yaitu, penelitian yang pernah dilakukan dalam kurun waktu 2009-2014, membahas kebijakan penyediaan air bersih dan sosial determinan. Penelusuran dilaksanakan dengan menggunakan fitur advance search. Kata kunci yang digunakan adalah livelihood assets AND water OR water use OR utilities OR resources AND urban OR slum AND social, dengan sasaran pada judul dan abstrak. Berdasarkan kata kunci yang dipilih tersebut telah ditemukan artikel yang membahas tentang kebijakan air bersih dan sosial determinan.

\section{HASIL}

Pada jurnal PubMed didapatkan 329 artikel dan pada Ebsco Host 176 artikel. Kemudian peneliti melakukan seleksi bedasarkan judul dan abstrak untuk 
memilih artikel spesifik yang membahas tentang air bersih untuk komunitas urban di permukiman kumuh. Didapatkan 10 artikel pada PubMed dan 3 pada Ebsco Host.

\section{PEMBAHASAN}

Penelitian dilaksanakan di kota yang terdapat di Amerika, Asia, Eropa, Afrika dan Australia. Kawasan Amerika yaitu Toronto (Canada), Guarulhos (Brazil), and Bogotá and Medellín (Colombia). Kawasan Asia meliputi Jordan, Shenyang City China dan Mumbai India, di Afrika diteliti di Durban, Eropa diteliti di Dublin capital of Ireland, dan di Australia diteliti di permukiman urban Australia.

Tabel Komponen Livelihoods Assets dan Kebijakan Politik Terhadap Permasalahan Akses Air Bersih Oleh Komunitas Urban di Permukiman Kumuh.

\begin{tabular}{|c|c|c|c|c|c|c|c|}
\hline \multirow[t]{2}{*}{ Tempat } & \multirow[t]{2}{*}{ Metode } & \multicolumn{5}{|c|}{ Livelihood Assets } & \multirow{2}{*}{$\begin{array}{c}\text { Kebijakan } \\
\text { Politik }\end{array}$} \\
\hline & & $\mathbf{H}$ & $\mathbf{N}$ & $\mathbf{S}$ & $\mathbf{F}$ & $\mathbf{P}$ & \\
\hline \multicolumn{8}{|l|}{ Kawasan Amerika } \\
\hline Americas & Deskriptif analitik & + & & & + & & + \\
\hline Brazil, Guarulhos & Deskriptif analitik & + & & & + & & + \\
\hline Canada, Toronto & Deskriptif analitik & + & & & + & & + \\
\hline $\begin{array}{l}\text { Colombia, Bogota \& } \\
\text { Medellin }\end{array}$ & Mix methode & + & & & + & + & + \\
\hline \multicolumn{8}{|l|}{ Eropa } \\
\hline $\begin{array}{l}\text { Irleland } \\
\text { Dublin }\end{array}$ & Simulation model & & & & + & + & + \\
\hline \multicolumn{8}{|l|}{ Asia } \\
\hline India & & & & & & & + \\
\hline Mumbai (Artikel 1.1) & Deskriptif/survai & & & & + & & \\
\hline Mumbai (artikel 1.2) & Deskriptif/survai & & & & + & & \\
\hline Mumbai (Artikel 1.3) & logistic regressions & & + & & & & \\
\hline Mumbai (Artikel 1.4) & logistic regressions & & + & & & & \\
\hline Jordan & Mix method & + & + & + & + & + & + \\
\hline $\begin{array}{l}\text { Northeast China, } \\
\text { Shenyang City }\end{array}$ & & & + & & & + & \\
\hline $\begin{array}{l}\text { South Africa } \\
\text { Durban }\end{array}$ & Qualitatif study & & & & & & + \\
\hline \multicolumn{8}{|l|}{ Australia } \\
\hline $\begin{array}{l}\text { Australia } \\
\text { Urban development area }\end{array}$ & Qualitatif study & & & & + & + & + \\
\hline
\end{tabular}

\section{Keterangan}

H: human capital (modal sumber daya manusia)

$\mathrm{N}$ : natural capital (modal sumber daya alam)

S: social capital (modal sosial)

F: financial capital (modal finansial)

P: physical capital (modal fisik)

\section{Human Capital (modal sumber daya manusia)}

Air jernih belum tentu memenuhi standar air minum dan tidak membahayakan kesehatan. Menurut WHO, standar air minum yang harus dipenuhi agar suatu persediaan air dapat dinyatakan layak, harus memenuhi persyaratan fisik, biologis, dan kimia. Standar fisik kualitas air meliputi suhu, warna, bau, rasa, kekeruhan. Standar biologis : kuman parasit, patogen, bakteri golongan Coliform, sedangkan standar kimia : $\mathrm{pH}$, jumlah zat padat, dan bahan kimia lain. Berdasarkan uraian tersebut diatas dapat diketahui bahwa aspek sumber daya manusia merupakan modal yang penting. Masyarakat dengan pemahaman yang benar memiliki kesadaran akan keterancaman dirinya, dan rasa yang tidak nyaman yang membahayakan tingkat kesehatan. Hal ini dapat menimbulkan upaya partisipatif membangun kesadaran bersama (awarenes) dan mempengaruhi 
pilihan penggunaan air bersih dalam kehidupan rumah tangga komunitas urban di permukiman kumuh.

Konteks sumber daya manusia menjadi tantangan dalam hal penggunaan air bersih terjadi di Jordan dan kawasan Americas (Guarulhos, Colombia, Bogota \& Medellin). Di Jordan komponen human, natural, financial dan phisycal capital secara bersama- sama mempengaruhi akses dan penggunaan air bersih, dilaporkan bahwa tinggginya persentase putus sekolah dan buta huruf adalah penyebab bagi mereka tinggal di daerah kumuh (khususnya para perempuan). Kondisi ini berakibat pada rendahnya daya saing mereka di dunia kerja, sehingga mempengaruhi aspek financial. Sedangkan kawasan Americas (Guarulhos, Colombia, Bogota \& Medellin), dilaporkan bahwa akses penggunaan air bersih dipengaruhi juga secara bersama oleh komponen kebijakan publik.

\section{Natural Capital (modal sumber daya alam)}

Air yang bersih dan layak menjadi kebutuhan pokok minimal sehari-hari untuk memenuhi kebutuhan hidup sehat dan produktif. Suplai air bersih menjadi sumber daya alam strategis multi sektoral yang menjadi bagian dalam segala aktivitas sosial ekonomi dan budaya masyarakat. Berdasarkan hasil review yang dilakukan, dilaporkan bahwa natural capital menjadi hambatan bagi distribusi air bersih kepada komunitas urban di kawasan permukiman kumuh. Kendala ini dialami oleh kota Mumbai, Jordan dan Shenyang City. Ketersediaan sumber suplai air bersih dipengaruhi oleh dua jenis faktor. Faktor pertama ketersediaan air sangat dipengaruhi oleh musim, dan faktor kedua karena tingginya kontaminasi akibat buruknya kualitas kesehatan lingkungan dan sanitasi.

Angin monsoon dan musim panas dilaporkan menjadi hambatan terhadap akses air bersih di Mumbai, India. WHO merekomendasikan konsumsi minimum air bersih adalah 50 liter per hari per kapita. Selama musim panas $50 \%$ sumber air berada dalam kondisi kering (lack) yang berakibat pada terjadinya kontaminasi oleh bakteri (E.Coli). Kondisi ini menyebabkan harga air bersih menjadi lebih mahal, sehingga konsumsi air bersih oleh komunitas urban menurun.

Berdasarkan hasil review dilaporkan bahwa hambatan terhadap tingkat konsumsi air bersih dipengaruhi oleh lingkungan yang tidak sehat karena tidak adanya sistem sanitasi dasar yang memadai, listrik dan fasilitas layanan kesehatan. Hal yang berbeda di temukan di Shenyang City, penelitian di Shenyang City dilakukan berdasarkan pendekatan social-ecological models, tekanan terhadap pemanfaatan sumber daya alam air bersih disebabkan oleh perubahan iklim dan pertumbuhan populasi serta urbanisasi.

\section{Social Capital (modal sosial)}

Carloni dan Crowly 2005 menyebutkan bahwa organisasi berbasis masyarakat adalah unsur kelembagaan di masyarakat yang berwujud kekerabatan, keturunan ,warisan, dan ikatan-ikatan tertentu yang berlaku di tingkat masyarakat dan di bawah kendali anggota community tersebut. Organisasi berbasis masyarakat bersifat informal, hidup di seluruh masyarakat dan sering kali tumpang tindih dengan lembaga sosial dalam di dalam struktur formal. Organisasi informal berbasis masyarakat dapat dibagi kedalam dua kategori besar (bentuk) yaitu : 
a. Lembaga yang memiliki fungsi sebagai komite. Lembaga ini berfungsi untuk mewakili kepentingan umum seluruh populasi penduduk dalam pengambilan keputusan, atau menentukan arah keputusan.

b. Lembaga yang bersifat Common Interest Groups (CIGs). Lembaga ini berfungsi mewakili kepentingan masyarakat yang bersifat private atau memiliki ketertarikan pada bidang yang sama/sejenis, misalnya perkumpulan arisan wanita, kelompok Tani, kelompok dagang asongan, dan lain sebagainya.

Melalui analisis peran modal sosial, akan dapat diketahui bagaimana hubungan antar rumah tangga atau individu dalam sistem (kekerabatan, sosial kelompok, keanggotaan dalam organisasi, ekonomi dan sosial keagamaan, kontak politik, patronase), dalam upaya meningkatkan akses air bersih bagi komunitas urban di permukiman kumuh. Analisis ini juga dapat membantu menerangkan tentang situasi apa yang membuat hubungan tersebut menjadi penting. Hasil review penelitian di Jordan menghasilkan rekomendasi bahwa untuk mengatasi tantangan permasalahan kesehatan, kemiskinan, pendidikan yang rendah, diskriminasi, kesehatan lingkungan dan kekurangan air bersih, maka perlu dilakukan perubahan strategi kebijakan melalui penguatan pemberdayaan masyarakat (empowerment), perlindungan sosial (social protection) dan partisipasi sosial (social inclusion).

Pemberdayaan masyarakat (empowerment) dilakukan dengan pengembangan program pemberdayaan perempuan berbasis masyarakat untuk kumuh daerah. Perlindungan sosial adalah upaya untuk mencegah pembentukan pemukiman kumuh baru dan memberikan warga kumuh prioritas kerja serta berkaitan juga dengan modal fisik yaitu mengembangkan penyediaan fasilitas air minum portabel, fasilitas sanitasi dasar, pelayanan kesehatan, pembangkit listrik pelayanan kesehatan hewan. Partisipasi sosial (social inclusion) dilakukan dengan memberikan hak bagi perempuan untuk memberikan kewarganegaraan kepada anak yang lahir dari seorang ayah non-Yordania, menyediakan semua warga kumuh dengan asuransi kesehatan dan mengurangi ketidaksetaraan dengan daerah-daerah lain.

\section{Financial Capital (modal finansial)}

Studi tentang aspek modal sumber daya ekonomi berfungsi untuk menjelaskan pola investasi masyarakat berkaitan dengan sumber pendapatan rumah tangga, pembiayaan kebutuhan hidup dasar dan skala prioritas. Hasil review menunjukkan bahwa hampir di semua artikel menyatakan bahwa faktor ekonomi mempengaruhi akses masyarakat terhadap air bersih. Kawasan kumuh identik dengan ciriciri dihuni oleh penduduk yang padat berpenghasilan rendah dan tidak tetap. Keputusan oleh rumah tangga berpenghasilan rendah untuk tidak berpartisipasi dalam community managed proyek air adalah karena adanya keterbatasan sumber daya ekonomi di tingkat rumah tangga. Pengaruh kontekstual pada partisipasi menunjukkan bahwa rumah tangga dengan hambatan ekonomi dan sosial yang relatif lebih sedikit umumnya lebih cenderung untuk berpartisipasi.

\section{Physical Capital (modal fisik)}

Studi aspek fisik berkaitan dengan ketersediaan dan pemeliharaan infrastruktur suplai air bersih di kawasan permukiman kumuh komunitas urban. Hasil review menjelaskan bahwa di Jordan, Americas, urban area Australia, Dublin 
dan Shenyang City, peningkatan modal sumber daya fisik menjadi kebutuhan untuk meningkatkan akses air bersih.

Sumber daya fisik yang dikembangkan adalah berupa sistem pemipaan, penyediaan air galon untuk keperluan minum dan memasak dan teknologi water recycle.

\section{Peran Kebijakan Politik}

Komponen livelihood assets adalah instrumen yang digunakan untuk memahami bagaimana sistem penghidupan berkelanjutan berinteraksi dengan lingkungan eksternal, yaitu berupa konteks kebijakan (policy) dan lingkungan alamiah (Carloni dan Crowly, 2005). Hal ini berarti bahwa peningkatan derajat kesehatan masyarakat melalui peningkatan akses air bersih dipengaruhi oleh keputusan politik. Achmadi (2013) menjelaskan bahwa politik pada dasarnya adalah mempelajari tentang kekuasaan dan alokasi sumber daya (modal). Barr et al. (2004) dalam Achmadi (2013) menyebutkan bahwa kesehatan adalah bagian dari politik karena derajat kesehatan atau permmasalahan kesehatan ditentukan oleh kebijakan yang dapat diarahkan atau mengikuti kehendak terhadap intervensi politik. Sebuah kebijakan turut menentukan arah untuk memudahkan masyarakat urban di daerah kumuh (slum area) untuk mendapatkan akses ke fasilitas air bersih, atau sebaliknya yaitu dapat mendiskriminasikan masyarakat, sehingga sulit bagi mereka untuk mendapatkan akses penggunaan air bersih.

\section{KESIMPULAN}

Interaksi komponen sustainable livelihood mempengaruhi pilihan penggunaan air bersih dalam kehidupan rumah tangga komunitas urban di permukiman kumuh. Tingginya angka buta huruf dan putus sekolah menjadi faktor penghambat dalam penggunaan air bersih.

Ketersediaan sumber suplai air bersih (natural capital) dipengaruhi oleh dua faktor, yaitu pergantian musim, dan tingginya kontaminasi akibat buruknya kualitas kesehatan lingkungan. Pada bidang social capital perlu dilakukan perubahan strategi kebijakan melalui penguatan pemberdayaan masyarakat (empowerment), perlindungan sosial (social protection) dan partisipasi sosial (social inclusion). Sumber daya fisik yang dikembangkan adalah berupa sistem pemipaan, penyediaan air gallon dan teknologi water recycle. Tekanan terhadap pemanfaatan sumber daya alam air bersih disebabkan oleh pertumbuhan populasi serta urbanisasi. Proses peningkatan derajat kesehatan masyarakat melalui peningkatan akses air bersih juga dipengaruhi oleh regulasi lokal dan keputusan politik.

\section{UCAPAN TERIMAKASIH}

Apresiasasi dan ucapan terimakasih penulis sampaikan kepada Fakultas Kedokteran Program Doktor Universitas Udayana, konsentrasi Ilmu Kesehatan Masyarakat (IKM), khususnya kepada para dosen dan guru besar yang telah membimbing dan mengarahkan penulis dalam membuat review ini. Harapan penulis melalui review ini dapat memberikan gambaran kepada pembaca dan peneliti tentang peran- peran modal yang menjadi bagian dari masyarakat dalam menentukan keberhasilan program dan kebijakan yang ditujukan untuk 
kepentingan peningkatan mutu kesehatan dan kualitas hidup masyarakat. Terimakasih.

\section{DAFTAR PUSTAKA}

1. Abadi, Moh. Fairuz. Pemetaan Kualitas Air Tanah di Desa Dauh Puri Kaja Kota Denpasar. Vol 6 No.2 Denpasar: ECOTROPHIC Jurnal Ilmu Lingkungan, 2011.

2. Achmadi Umar Fahmi Kesehatan Masyarakat Teori dan Aplikasinya. PT RajaGrafindo Persada. Jakarta, 2013.

3. Ajlouni, M.T. Social Determinants Of Health In Selected Slum Areas In Jordan: Challenges And Policy Directions. The International journal of health planning and management. Available at: http://www.ncbi.nlm.nih.gov/pubmed/252802 [Accessed November 5, 2014], 2014.

4. Carloni, Alice Stewart dan Eve Crowly. Rapid Guide For Missions Analysing Local Institution And Livelihoods. Rome: FAO of The United Nation, 2005.

5. Das, P. \& Takahashi, L. Non-participation of low-income households in community- managed water supply projects in India. International Development Planning Review, (3), pp.265-291. Available at: http://liverpool.metapress.com/openurl.asp? gere=article\&id=doi:10.3828/i dpr.2014.16 [Accessed November 5, 2014], 2014.

6. Ismawan, D.A. Kajian Kerentanan Kawasan Permukiman Padat Terhadap Bencana Kebakaran Di Kecamatan Tambora - Jakarta Barat. Jurusan Perencanan Wilayah Dan Kota Fakultas Teknik Universitas Diponegoro, 2008.

7. Loftus, A.Rethinking Political Ecologies of Water. Third World Quarterly, $30(5)$. Available at: http://www.tandfonline.com/doi/abs/10.1080/01436590902959198 [Accessed October 15, 2014], 2009: 953-968.

8. Krantz Lasse. The SustainableLivelihoodApproach to Poverty Reduction An Introduction. Division for Policy and Socio-Economic Analysis. Swedish International Development Cooperation Agency, 2011.

9. Murthy, S.L. Land security and the challenges of realizing the human right to water and sanitation in the slums of Mumbai, India. Health and human rights, 14(2). Available at: http://www.ncbi.nlm.nih.gov/pubmed/23568948 [Accessed November 5, 2014], $2012:$ 61-73.

10. Prasad, A. et al. Linking evidence to action on social determinants of health using Urban HEART in the Americas. Revista panamericana de salud pública $=$ Pan American journal of public health, 34(6). Available at: http://www.ncbi.nlm.nih.gov/pubmed/24569969 [Accessed November 5, 2014], 2013: 407-15.

11. Qi, C. \& Chang, N.-B. System dynamics modeling for municipal water demand estimation in an urban region under uncertain economic impacts. Journal of environmental management, 92(6), pp.1628-41. Available at: http://www.ncbi.nlm.nih.gov/pubmed/21324581 [Accessed October 15, 2014], 2011. 
12. Rodríguez-Villamil, N., Restrepo-Mesa, S. \& Zambrano-Bejarano, I., The lack of water and its implications regarding feeding practice in Turbo, Antioquia. Revista de salud pública (Bogotá, Colombia), 15(3), pp.421-33. Available at: http://www.ncbi.nlm.nih.gov/pubmed/25124000 [Accessed November 5, 2014].

13. Sharma, A.K. et al. Impediments and constraints in the uptake of water sensitive urban design measures in greenfield and infill developments. Water science and technology : a journal of the International Association on Water Pollution Research, 65(2), pp.340-52. Available at: http://www.ncbi.nlm.nih.gov/pubmed/22233914 [Accessed November 5, 2014], 2012.

14. Subbaraman, R. et al., 2013. The social ecology of water in a Mumbai slum: failures in water quality, quantity, and reliability. BMC public health. Available at: http://www.pubmedcentral.nih.gov/articlerend er.fcgi? artid=3599692\&tool=pmcentrez\&rend ertype=abstract [Accessed September 30, 2014], 2013:173

15. Turley, R. et al. Slum upgrading strategies involving physical environment and infrastructure interventions and their effects on health and socioeconomic outcomes. The Cochrane database of systematic reviews, 1, p.CD010067. Available at: http://www.ncbi.nlm.nih.gov/pubmed/234408 [Accessed November 4, 2014], 2013.

16. Wade, J.S. The future of urban water services in Latin America. Bulletin of Latin American research, 31(2). Available at: http://www.ncbi.nlm.nih.gov/pubmed/22530259 [Accessed November 5, 2014], 2012: 207-21

17. Wang, J. et al. Calculation model of urban water resources ecological footprint and its application: a case study in Shenyang City of Northeast China. Ying yong sheng tai xue bao = The journal of applied ecology / Zhongguo sheng tai xue xue hui, Zhongguo ke xue yuan Shenyang ying yong sheng tai yan jiu suo zhu ban, 23(8), pp.2257-62. Available at: http://www.ncbi.nlm.nih.gov/pubmed/23189707 [Accessed November 5, 2014], 2012.

18. Wang, M.-E., Chen, W.-P. \& Peng, C. Urban ecological risk assessment: a review. Yingyong sheng tai xue bao $=$ The journal of applied ecology / Zhongguo sheng tai xue xue hui, Zhongguo ke xue yuan Shenyang ying yong sheng tai yan jiu suo zhu ban, 25(3), pp.911-8. Available at: http://www.ncbi.nlm.nih.gov/pubmed/24984514 [Accessed November 5, 2014], 2014.

19. Willuweit, L. \& O'Sullivan, J.J.. A Decision Support Tool For Sustainable Planning Of Urban Water Systems: Presenting The Dynamic Urban Water Simulation Model. Water research, 47(20), pp.7206-20. Available at: http://www.ncbi.nlm.nih.gov/pubmed/241835 60 [Accessed October 22, 2014], 2013. 